\title{
A Comparative Study between the Effect of Ropinirole and Metformin on Metabolic Syndrome in Women
}

\author{
Faruk H. AL-Jawad ${ }^{1 *}$, Yaseen O.yaseen ${ }^{2}$, Fouad K. Gatea ${ }^{3}$, Ali Khalaf Hoshi ${ }^{3}$ \\ ${ }^{1}$ Professor, Department of Pharmacology \& Therapeutics, Al -Nahrain College of Medicine, Al Jadriyah Bridge, Baghdad 64074, Iraq \\ ${ }^{2}$ Professor, Department of Medicine, Missan College of Medicine, Iraq \\ ${ }^{3}$ Lecturer Department of Pharmacology \& Therapeutics, Al -Nahrain College of Medicine, Al Jadriyah Bridge, Baghdad 64074, Iraq
}

DOI: $\underline{10.36347 / \text { sajp.2020.v09i08.001 }}$

| Received: 29.04.2020 | Accepted: 07.05.2020 | Published: 05.08.2020

*Corresponding author: Faruk H. AL-Jawad

\section{Abstract}

Original Research Article

Background: Metabolic syndrome is a multiplex risk factor that arises from hyperglycemia /insulin resistance accompanied with abnormal fat function \&central obesity\& possibility to develop diabetes mellitus type-2, atherosclerosis \& various diseases. Aim of study: To determine the effect of ropinirole \& metformin on glycemic Parameters, insulin sensitivity and lipid profile associated with metabolic syndrome. Patients and methods: The present study was performed in diabetic and endocrine center from May 2016 to march 2018. Ninety female patients with metabolic syndrome participate in this study. They were allocated to three groups (each group contain 30 patients) first group put on diet restriction physical exercise only. Second group received metformin $750 \mathrm{mg}$ extended release orally once daily at night with diet restriction \& physical exercise. Third group received ropinirole $0.25 \mathrm{mg}$ orally after meal in morning with diet restriction \& physical exercise. The duration of the study extended to 12 weeks. Blood samples were taken from each patient at zero time to determine base line level \& after 12 weeks of treatment. The measured parameters were WBC, BMI, FBS, FI, HOMA-IR, Hb A1c, TC, TG, HDL, LDL. Results: Showed highly significant lowering effect of both ropinirole \& metformin on the levels of the all parameters except HDL with high significant elevation, at the mean time all the parameters of the control were significantly changed. Conclusion: Both drugs improve glycemic parameters, insulin sensitivity and lipid profile in metabolic syndrome but metformin is slightly more powerful on these parameters.

Keywords: Ropinirole, metformin, metabolic syndrome, insulin resistance, lipid profile.

Copyright @ 2020: This is an open-access article distributed under the terms of the Creative Commons Attribution license which permits unrestricted use, distribution, and reproduction in any medium for non-commercial use (NonCommercial, or CC-BY-NC) provided the original author and source are credited.

\section{INTRODUCTION}

Metabolic syndrome (M.S) is a clustering of clinical components including hyperglycemia/insulin resistance obesity and dyslipidemia [1]. The international diabetes foundation (IDF) published new criteria for definition \& diagnosis of metabolic syndrome. It include increase the waist circumference (WTC) and FBS \&TG levels and decrease of HDL level and rise of blood pressure [2]. The present study was performed to explore the possible effect of Ropinirole $\&$ metformin on M. S. Ropinirole is a selective non ergoline pure dopamine D2 receptor agonist, it has negligible affinity for dopamine D1 receptor it used in treatment of Parkinsonism [3]. While metformin is an antidiabetic drug related to biguanides group, its primary effect is to activate the enzyme AMP that activated protein kinase (AMDK) and to reduce hepatic glucose production used in polycystic ovary disease [4].

\section{PATIENTS \& MATERIALS \& METHODS}

The present study conducted at endocrine \& diabetes center from may 2016 to march 2018 after approval by ethical committee of Al-nahrain College of medicine.

\section{Chemicals}

All the chemicals used in the present study were of analytic grade. Ropininole $0.5 \mathrm{mg}$ tab. Supplied by IDIR Ranbaxy Company. Metformin $750 \mathrm{mg}$ XR supplied by Merch Germany. Kits for TC,HDL,LDL,TG purchased by accent 2000 poland. HBA1c supplied by Bio-Rad lab USA. Insulin Elisa. Tohso.

Patients

Ninety female patients participated in this study. They were selected according to the definition of IDF for M.S. They were informed about the aim of the study. The range of the patient's age was between 26-45 
years old. All the patients with other diseases were excluded from the study .patients were allocated to three groups (each group contain 30 patients). The first group (control) received no medication but put on diet restriction \& physical exercise only. Second group: received metformin $750 \mathrm{mg}$ extended release orally once daily at night in addition to diet restriction \& physical exercise. Third group: received Ropinirole $0.25 \mathrm{mg}$ orally after meal in the morning with diet restriction and physical exercise. The following parameters were measured in all the participants starting from zero time (base line) \& continued for 12 weeks for each parameter WTC (waist circumference) BMI (body mass index) FBS (fasting blood sugar) FI (fasting insulin) lipid profile total cholesterol, TG, HDL, LDL, VLDL) Hemoglobin A1c (HBA1c) HOMA-IR (hemostatic mode assessment for insulin resistance) blood pressure was measured every 4 hours. After fasting the patient for 12 hours, $10 \mathrm{ml}$ of venous blood collected at each visit. $2 \mathrm{ml}$ of the whole blood anticoagulant tube used for HBA1c measured at zero time \& after 12 weeks. The other part was obtained in plasma tube \& centrifuged. $10 \mathrm{~min}$ to separate the serum in order to be used in spectrophotometer method [5].

\section{Statistical Analysis}

The results of the study were analyzed by using (SPSS) methods.

The paired T- Dependent test used for comparing the results of same group \& independent $\mathrm{T}$ test used for comparing between different groups\& the statistical signification was $\mathrm{p}<0.05$.

\section{RESULTS}

The obtained results revealed that both metformin \& Ropinirole groups produce highly significant reduction $\mathrm{P}<0.001$ in the levels of $\mathrm{WTC}$ and BMI \& FBS and FI\& HBA1c and HOMA-IR also TC, TG, LDL, LVDL, except HDL which is highly elevated significantly $p<0.001$ when the results of the base line compared with the results after 12 weeks of treatment. In general metformin has more potent effect than Ropinirole on these parameters. At the meantime the control group produce significant lowering effect of FBS,FI,HBA1c,HOMA-IR levels $\mathrm{p}<0.05$ with highly significant effect of WTC, BMI \& LIPID profile $\mathrm{p}<0.001$ see Table $1,2,3,4$.

Table-1: The effect of control, metformin and ropinirole groups on the WTC and BM index after 12 weeks of treatment

\begin{tabular}{|l|l|l|l|l|}
\hline \multirow{2}{*}{ Parameters } & Period & Control & Metaformin & Ropinirole \\
\hline Waist circumference (WTC) $(\mathrm{cm})$ & & & & \\
\cline { 2 - 5 } & Base line & $122.73 \pm 1.20$ & $125.26 \pm 1.68$ & $125.90 \pm 1.78$ \\
\cline { 2 - 5 } & 12 weeks & $104.32 \pm 1.01^{* *}$ & $93.95 \pm 1.26^{* *}$ & $96.94 \pm 1.37^{* *}$ \\
\cline { 2 - 5 } & $\Delta$ WTC & $-18.41 \pm 0.17$ & $-31.13 \pm 0.42^{\text {ab }}$ & $-30.21 \pm 0.42^{\text {ab }}$ \\
\hline Body mass index km/m ${ }^{2}$ & baseline & $35.59 \pm 0.41$ & $36.98 \pm 1.17$ & $38.53 \pm 1.45$ \\
\cline { 2 - 5 } & 12 weeks & $30.61 \pm 0.35^{*}$ & $27.73 \pm 0.88^{* *}$ & $32.54 \pm 1.27^{* *}$ \\
\cline { 2 - 5 } & $\Delta$ BMI & $-4.98 \pm 0.31$ & $-9.24 \pm 0.29^{\text {ab }}$ & $-5.99 \pm 0.35^{\text {ab }}$ \\
\hline
\end{tabular}

*Significant at $\mathrm{p}<0.05 * *$ highly significant at $\mathrm{p}<0.001$ comparing with the base line level by using a paired $t-$ test a significant at $\mathrm{P}<0.05$ ab highly significant at $\mathrm{P}<0.001$ comparing changes of drugs and control by using unpaired $\mathrm{t}$ test. $\Delta$ changing in the base line.

Table-2: The effect of control, metformin and ropinirole groups on the FBS and FI levels after 12 weeks of treatment

\begin{tabular}{|l|l|l|l|l|}
\hline \multirow{2}{*}{ Parameters } & Period & Control & Metformin & Ropinirole \\
\hline Fasting blood sugar FBS mg/dl & & & & \\
\cline { 2 - 5 } & Base line & $115.2 \pm 5.74$ & $117.1 \pm 5.74$ & $119.06 \pm 5.74$ \\
\cline { 2 - 5 } & 12 weeks & $110.62 \pm 0.66^{*}$ & $93.68 \pm 0.72^{* *}$ & $108.59 \pm 0.68^{* *}$ \\
\cline { 2 - 5 } & $\Delta$ FBS & $-4.57 \pm 1.29$ & $-23.42 \pm 0.18^{\text {ab }}$ & $-18.47 \pm 0.10^{\text {ab }}$ \\
\hline \multirow{3}{*}{ Fasting insulin FI IU/ml } & baseline & $48.36 \pm 1.08$ & $49.26 \pm 1.51^{* *}$ & $48.40 \pm 1.33$ \\
\cline { 2 - 5 } & 12 weeks & $38.77 \pm 0.92^{*}$ & $27.63 \pm 0.75^{* *}$ & $29.04 \pm 0.79^{* *}$ \\
\cline { 2 - 5 } & $\Delta$ FI & $-9.59 \pm 1.66$ & $-24.63 \pm 0.75^{\text {ab }}$ & $-19.36 \pm 0.53^{\text {ab }}$ \\
\hline
\end{tabular}

*Significant at $\mathrm{p}<0.05 * *$ highly significant at $\mathrm{p}<0.001$ comparing with the base line level by using a paired t- test a significant at $\mathrm{P}<0.05$ ab highly significant at $\mathrm{P}<0.001$ comparing changes of drugs and control by using unpaired $\mathrm{t}-$ test. $\Delta$ changing in the base line. 
Table-3: The effect of control, metformin and ropinirole groups on the HbA1c and HOMA-IR after 12 weeks of treatment

\begin{tabular}{|c|c|c|c|c|}
\hline $\begin{array}{ll}\text { Parameters } & \text { Groups } \\
\end{array}$ & Period & Control & Metformin & Ropinirole \\
\hline \multirow[t]{3}{*}{ Glycosylated Hemoglubin ( HbA1c) } & Base line & $6.43 \pm 0.12$ & $6.13 \pm 0.05$ & $6.34 \pm 0.08$ \\
\hline & 12 weeks & $5.82 \pm 0.09^{*}$ & $5.21 \pm 0.04^{* *}$ & $5.64 \pm 0.07^{* *}$ \\
\hline & $\Delta \mathrm{HbA} 1 \mathrm{C}$ & $-0.61 \pm 0.11$ & $-0.92 \pm 0.01^{a b}$ & $-0.69 \pm 0.08^{a b}$ \\
\hline \multirow{3}{*}{$\begin{array}{l}\text { Homeostatic mode assessment for insulin } \\
\text { resistance ( HOMA-IR ) }\end{array}$} & baseline & $13.77 \pm 0.35$ & $14.26 \pm 0.47$ & $14.18 \pm 0.33$ \\
\hline & 12 weeks & $10.58 \pm 0.20$ & $5.70 \pm 0.18^{* * *}$ & $4.70 \pm 0.16^{* *}$ \\
\hline & $\Delta$ HOMA-IR & $-3.19 \pm 1.66$ & $-8.55 \pm 0.28^{a b}$ & $-6.78 \pm 0.45^{a b}$ \\
\hline
\end{tabular}

$*$ Significant at $\mathrm{p}<0.05 * *$ highly significant at $\mathrm{p}<0.001$ comparing with the base line level by using a paired $\mathrm{t}-$ test a significant at $\mathrm{P}<0.05$ ab highly significant at $\mathrm{P}<0.001$ comparing changes of drugs and control by using unpaired $\mathrm{t}-$ test. $\Delta$ changing in the base line.

Table-4: The effect of control, metformin and ropinirole groups on the lipid profile after 12 weeks of treatment

\begin{tabular}{|c|c|c|c|c|}
\hline $\begin{array}{ll}\text { Parameter } & \text { Groups } \\
\end{array}$ & Period & Control & Metformin & Ropinirole \\
\hline \multirow[t]{3}{*}{ Total cholesterol (TC) mg/dl } & Base line & $277.56 \pm 6.92$ & $295.13 \pm 6.70$ & $288.33 \pm 6.54$ \\
\hline & 12 weeks & $246.07 \pm 5.3^{* * *}$ & $177.08 \pm 4.02^{* *}$ & $199.31 \pm 3.59^{* * *}$ \\
\hline & $\Delta \mathrm{TC}$ & $-31.49 \pm 1.39$ & $-118.05 \pm 2.68^{a b}$ & $-89.01 \pm 1.93^{a b}$ \\
\hline \multirow[t]{3}{*}{ Triglyceride (TG) mg/dl } & baseline & $271.4 \pm 6.5$ & $277.33 \pm 7.05$ & $289.93 \pm 8.38$ \\
\hline & 12 weeks & $216.9 \pm 8.05^{* * *}$ & $148.5 \pm 4.12^{* *}$ & $171.06 \pm 4.94^{* * *}$ \\
\hline & $\Delta \mathrm{TG}$ & $-31.49 \pm 1.39$ & $-128.83 \pm 5.8^{a b}$ & $-118.87 \pm 3.43^{\mathrm{a}}$ \\
\hline \multirow[t]{3}{*}{ Low Density Lipoprotein (LDL) mg/dl } & Base line & $150.30 \pm 5.75$ & $158.43 \pm 5.07$ & $153.83 \pm 5.74$ \\
\hline & 12 weeks & $127.75 \pm 4.89^{* * *}$ & $95.06 \pm 3.04^{* *}$ & $99.99 \pm 3.73^{* * *}$ \\
\hline & $\Delta \mathrm{LDL}$ & $-22.54 \pm 0.86$ & $-63.37 \pm 2.02^{a b}$ & $-53.84 \pm 2.01^{a b}$ \\
\hline \multirow[t]{3}{*}{ Very Low Density Lipoprotein (VLDL) mg/dl } & baseline & $54.28 \pm 1.3$ & $57.84 \pm 1.84$ & $57.99 \pm 1.67$ \\
\hline & 12 weeks & $43.38 \pm 1.70^{*}$ & $29.92 \pm 0.98^{* *}$ & $41.37 \pm 1.10^{* *}$ \\
\hline & $\Delta \mathrm{VLDL}$ & $-11.85 \pm 0.15$ & $-17.88 \pm 0.68^{a b}$ & $-16.61 \pm 0.29^{a}$ \\
\hline \multirow[t]{3}{*}{ High Density Lipoprotein (HLDL) mg/dl } & Base line & $33.4 \pm 0.61$ & $37.16 \pm 1.34$ & $30.76 \pm 0.97$ \\
\hline & 12 weeks & $41.75 \pm 0.76^{* * *}$ & $52.03 \pm 1.88^{* *}$ & $39.99 \pm 1.26^{* * *}$ \\
\hline & $\Delta \mathrm{HDL}$ & $8.35 \pm 0.15$ & $15.53 \pm 1.33^{\mathrm{ab}}$ & $9.23 \pm 0.29^{\mathrm{ab}}$ \\
\hline
\end{tabular}

$*$ Significant at $\mathrm{p}<0.05 * *$ highly significant at $\mathrm{p}<0.001$ comparing with the base line level by using a paired $t-$ test a significant at $\mathrm{P}<0.05$ ab highly significant at $\mathrm{P}<0.001$ comparing changes of drugs and control by using unpaired $\mathrm{t}-$ test. $\Delta$ changing in the base line.

\section{DISCUSSION}

In the present study all the patients with M.S were put on diet restriction \& physical exercise but patients of group1(control) received no medication, the diet and exercise therapy are change in group1 to produce significant lowering effect in body weight, WTC \& BMI considerably after 12 weeks of the treatment when compared with zero time (base line). The exercise therapy activates AMDK enzyme to induce favorable metabolic changes in muscle\& adipose tissue using fat as energy source instead of storing it [6] meanwhile FBS, FI, HBA1c, HOMA-IR were significantly reduced when compared with base line after 12 weeks of diet changes \& exercise therapy due to increase fuel utilization \& enhance glycolysis in skeletal muscles [7] our results were compatible with the results of others [8-10].

At the same time the results of lipid profile revealed highly significant reduction in TC, TG, and LDL levels with highly significant increase in HDL level these results were compatible with results of others for the same reasons [11].
Metformin is exerted highly significant lowering effect on body weight, BMI \& WTC (group 2) due to its multiple effects in suppressing glucose hepatic production, inhibition of glucose absorption from the gut \& improvement of glycolysis with anorexic effect [12]. Metformin extended release make the body accelerates fatty acid oxidation in the cell especially at night to compensate the reduction in glucose which is important substrate of energy [13].

Metformin promoted weight loss \& BMI\&WTC in patients with obesity in DM-type 2 after 12 weeks of treatment. Our results were similar to the results of others [14]. Metformin showed highly significant reduction in FBS, FI, HOMA-IR \& HBA1c after 12 weeks of treatment due to inhibition of hepatic glucose production \& decline in insulin level these results were similar to results of others [15].

Metformin improve insulin sensitivity by several mechanisms include increasing insulin receptor tyrosine kinase activity, enhancing glycogen synthesis 
\& increasing expression of GLUT \& glucose transporter [16].

Metformin showed remarkable reduction in serum cholesterol, TG, VLDL, LDL with highly significant elevation in HDL level in the base line level. These effects attributed to insulin resistance that lead to increase amount of free fatty acid infiltrate to the liver. Therefor increase TG as well as VLDL production. These results were compatible with the results of other researchers [17]

Metformin therapy may increase the lipoprotein, lipase production. Therefore increase HDL that reduce the risk of atherosclerosis [18].

Administration of Ropinirole to patients with insulin resistance produced high significant lowering effect of body weight, BMI, WTC in group-3 this reduction attributed to the ability of D2-receptor agonist in shifting the energy utilization toward fatty acid oxidation as a result more stored fat will consumed that lead to weight loss \& change of BMI,WTC. These results were similar to results of others when they used cabergoline as D2-receptor agonist [19]. Ropinirole has an effect on appetite producing a state of anorexia \& nausea that lead to weight loss [20].

In the present study ropinirole caused highly significant decline in FBS\& FI levels compared with base line during 12 weeks of treatment, this lead to decrease HOMA-IR which is index of insulin resistance and also HBA1c decreased. These results compatible with the results of others [21] when they used cabergoline in study that cause significant decrease in FBS \& HBA1c.

Ropinirole showed highly significant changes in lipoproteins after 12 weeks of treatment decreasing TC, TG, LDL, VLDL and increasing HDL levels, these changes related to improving insulin sensitivity, decreasing body weight, shifting the energy utilization, lowering of FFA oxidation \& inhibition of lipolysis, these results were compatible with results of $[22,23]$ who noticed that cabergoline reducing $\mathrm{TG}$ and increasing HDL.

\section{CONCLUSION}

Both metformin \& Ropinirole improve glycemic parameters, insulin sensitivity \& lipid profile in metabolic syndrome but metformin has more powerful effects on these parameters.

\section{REFERENCES}

1. Putnam K, Shoemaker R, Yiannikouris F, Cassis LA. The renin-angiotensin system: a target of and contributor to dyslipidemias, altered glucose homeostasis, and hypertension of the metabolic syndrome. American Journal of Physiology-Heart and Circulatory Physiology. 2012 Mar 15;302(6):H1219-30.

2. O'neill S, O'driscoll L. Metabolic syndrome: a closer look at the growing epidemic and its associated pathologies. Obesity reviews. 2015 Jan;16(1):1-2.

3. Aminoff MJ. Pharmocologic management of Parkinsonism \&other movement disorders. Basic \& clinical pharmacology ed. Katzung \& trevor, $13^{\text {th }}$ ed. 2015, 487 Mc graw-hill education Lange.

4. Richard F, Michelle AC, Luigi X. Cubedde oral agents, insulin sensitizers Lippincotts illustrated Reviewers. Pharmacology $6^{\text {th }}$ ed. 2015 wolters kluwer. William \& wilkins, biguaides.

5. Burtis CA, Ashood ER. Text book of clinical chemistry $3^{\text {rd }}$ ed. Vol 2 sandercomp. 1999; 1059. 1060

6. Mikusova L, Sturdik E, Mosovska S, Bobrík M. Biochemical aspects of exercise in prevention of overweight and obesity. Acta Chimica Slovaca. 2009;2(2):97-119.

7. Hue L, Taegtmeyer H. The Randle cycle revisited: a new head for an old hat. American Journal of Physiology-Endocrinology and Metabolism. 2009 Sep;297(3):E578-91.

8. IVY A, Rodriguez F, Garcia C, Chen M. Non adrenergic \& serotonergic blockade inhibits BDNF mRNA activation folowing exerscise \& antideprenants. Pharmaco biochem \& behavior, 2003;75(1):81-88.

9. Fontana L, Villareal DT, Weiss EP, Racette SB, Steger-May K, Klein S, Holloszy JO. Calorie restriction or exercise: effects on coronary heart disease risk factors. A randomized, controlled trial. American Journal of Physiology-Endocrinology and Metabolism. 2007 Jul;293(1):E197-202.

10. Gordon LA, Morrison EY, McGrowder DA, Young R, Fraser YT, Zamora EM, AlexanderLindo RL, Irving RR. Effect of exercise therapy on lipid profile and oxidative stress indicators in patients with type 2 diabetes. BMC complementary and alternative medicine. 2008 Dec;8(1):21.

11. Razay G, Vreugdenhil A, Wilcock G. The metabolic syndrome and Alzheimer disease. Archives of neurology. 2007 Jan 1;64(1):93-6.

12. Greenway SC. Human energy metabolism in health and disease. Functional Metabolism Regulation and Adaptation. 2004 Aug 2;243:271.

13. Freemark M, Bursey D. The Effects of Metformin on Body Mass Index and Glucose Tolerance in Obese Adolescents with Fasting Hyperinsulinemia and a Family History of Type 2 Diabetes. Pediatrics, 2001, 107(4):e55-e65.

14. Campagnoli $\mathrm{C}$, Pasanisi $\mathrm{P}$, Abbà $\mathrm{C}$, Ambroggio $\mathrm{S}$, Biglia N, Brucato T, Colombero R, Danese S, Donadio M, Venturelli E, Zito G. Effect of different doses of metformin on serum testosterone and insulin in non-diabetic women with breast 
cancer: a randomized study. Clinical breast cancer. 2012 Jun 1;12(3):175-82.

15. Mughal M A, Jan M, Maheri W M, Memon M Y, Ali M. The Effect of Metformin on Glycemic Control, Serum Lipids and Lipoproteins in diet alone and Sulfonylurea-treated type 2 Diabetic Patients with Sub-Optimal Metabolic Control. (J PMA) Journal of Pakistan Medical Association, 2000, 50(11):381-386.

16. Giannarelli R, Aragona M, Coppelli A, Del Prato S. Reducing insulin resistance with metformin: the evidence today. Diabetes \& Metabolism. 2003; 29(4):6S28-35.

17. Ohira M, Miyashita Y, Ebisuno M, Saiki A, Endo K, Koide N, Oyama T, Murano T, Watanabe H, Shirai K. Effect of metformin on serum lipoprotein lipase mass levels and LDL particle size in type 2 diabetes mellitus patients. Diabetes research and clinical practice. 2007 Oct 1;78(1):34-41.

18. Assad HC, Mosah HA, Hashim HM, Khazaal FA. Effect of Cabergoline added to Metformin on Glycemic Control, Insulin Resistance and Beta Cell Function in Obese type 2 Diabetic Patients. Global Journal of Medical Research. 2014 Oct 25.
19. Frank GK. Could dopamine agonists aid in drug development for anorexia nervosa?. Frontiers in nutrition. 2014 Nov 3;1:19.

20. Saadat N, Esmaily H, Abbasinazari M, Tohidi M, Salamzadeh J, Hadaegh F, Tolabi M, KalantarHormozi M, Dibaj M. Does twice-weekly cabergoline improve anthropometrical and biochemical profiles in prediabetes? A randomized double-blind clinical trial pilot study. Iranian journal of pharmaceutical research: IJPR. 2015;14(Suppl):77-86.

21. Auriemma RS, Granieri L, Galdiero M, Simeoli C, Perone Y, Vitale P, Pivonello C, Negri M, Mannarino T, Giordano C, Gasperi M. Effect of cabergoline on metabolism in prolactinomas. Neuroendocrinology. 2013;98(4):299-310.

22. Krysiak R, Okopien B. Different Effects Of Cabergoline and Bromocriptine on Metabolic and Cardiovascular Risk Factors in Patients with Elevated Prolactin Levels. Basic \& Clinical Pharmacology \& Toxicology. 2015, 116(3):251256. 